\title{
ÍNDICE DO volume 95 RBEP
}

Este índice refere-se às matérias do volume 95 (números 239, 240 e 241) da Revista Brasileira de Estudos Pedagógicos. Divide-se em três partes, de acordo com os diferentes pontos de acesso: Assuntos, Autores e Títulos.

Quanto ao Índice de Assuntos:

- os termos usados para indexação são extraídos do Thesaurus Brasileiro de Educação (Brased);

- cada palavra dos termos compostos abre uma entrada, por exemplo:

Avaliação do ensino superior
ensino superior, Avaliação do
superior, Avaliação do ensino

Quanto ao Índice de Autores:

- arrolados pelo último sobrenome;

- um traço é usado para substituir o nome quando há mais de uma entrada para o mesmo autor.

Quanto ao Índice de Títulos:

- os artigos que iniciam o título não são considerados. 



\section{ÍNDICE DE ASSUNTOS RBEP}

Acesso ao ensino superior - desempenho acadêmico - intervenção pedagógica

FAGUNDES, Caterine Vila. Percepção dos estudantes universitários acerca do acesso à educação superior: um estudo exploratório. RBEP, Brasília, DF, v. 95, n. 241, p. 508-525, set./dez. 2014. Seção: Estudos.

Acesso ao ensino superior - formação acadêmica - Programa Universidade para todos (ProUni)

FELICETTI, Vera Lucia. Comprometimento do aluno ProUni: acesso, persistência e formação acadêmica. RBEP, Brasília, DF, v. 95, n. 241, p. 526543, set./dez. 2014. Seção: Estudos.

Acesso ao ensino superior - políticas públicas em educação - ensino médio

CARMO, Erinaldo Ferreira et al. Políticas públicas de democratização do acesso ao ensino superior e estrutura básica de formação no ensino médio regular. RBEP, Brasília, DF, v. 95, n. 240, p. 304-327, maio/ago. 2014. Seção: Estudos.

Antropologia educacional - ensino superior - inclusão educacional SILVA, Jefferson Olivatto da. Ações inclusivas no ensino superior brasileiro. RBEP, Brasília, DF, v. 95, n. 240, p. 414-430, maio/ago. 2014. Seção: Estudos. 


\section{Aprendizagem - psicomotricidade - ensino de matemática}

FERNANDES, Cleonice Terezinha; DANTAS, Paulo Moreira Silva; MOURÃOCARVALHAL, Maria Isabel. Desempenho psicomotor de escolares com dificuldades de aprendizagem em cálculos. RBEP, Brasília, DF, v. 95, n. 239, p. 112-138, jan./abr. 2014. Seção: Estudos.

\section{Atuação docente - educação básica - ensino de Língua Portuguesa} MAGALHAES, Tânia Guedes; CYRANKA, Lucia Furtado de Mendonça. Sujeito, educação e o trabalho com a Língua Portuguesa na escola básica. RBEP, Brasília, DF, v. 95, n. 241, p. 662-675, set./dez. 2014. Seção: Estudos.

Atuação docente - ensino de matemática - classe multisseriada escola ribeirinha

OLIVEIRA, José Sávio Bicho de; LUCENA, Isabel Cristina Rodrigues de. Alfabetização matemática em classes multisseriadas de escolas ribeirinhas da Amazônia: atuação docente em foco. RBEP, Brasília, DF, v. 95, n. 239, p. 87-111, jan./abr. 2014. Seção: Estudos.

\section{Base de conhecimento - ensino de Educação Física}

MARTINY, Luis Eugênio; GOMES-DA-SILVA, Pierre Normando. A transposição didática na educação física escolar: o caminho formativo dos professores em formação inicial. RBEP, Brasília, DF, v. 95, n. 239, p. 175196, jan./abr. 2014. Seção: Estudos.

\section{Ceticismo - estoicismo - fundamentação da educação - Michel de Montaigne}

BATISTA, Gustavo Araújo. Montaigne: a fundamentação da educação nos moldes céticos e estoicos. RBEP, Brasília, DF, v. 95, n. 241, p. 497-507, set./ dez. 2014. Seção: Estudos.

\section{Classe multisseriada - educação no campo - prática pedagógica - perfil docente}

PARENTE, Cláudia da Mota Darós. Perfil, concepções e práticas pedagógicas de professores que atuam em turmas multisseriadas de escolas públicas de Sergipe. RBEP, Brasília, DF, v. 95, n. 241, p. 676-695, set./dez. 2014. Seção: Estudos.

Classe multisseriada - ensino de matemática - escola ribeirinha Amazônia - atuação docente

OLIVEIRA, José Sávio Bicho de; LUCENA, Isabel Cristina Rodrigues de. Alfabetização matemática em classes multisseriadas de escolas ribeirinhas da Amazônia: atuação docente em foco. RBEP, Brasília, DF, v. 95, n. 239, p. 87-111, jan./abr. 2014. Seção: Estudos.

\section{Competência psicomotora - psicomotricidade - aprendizagem - ensino} de matemática FERNANDES, Cleonice Terezinha; DANTAS, Paulo Moreira Silva; MOURÃOCARVALHAL, Maria Isabel. Desempenho psicomotor de escolares com dificuldades de aprendizagem em cálculos. RBEP, Brasília, DF, v. 95, n. 239, p. 112-138, jan./abr. 2014. Seção: Estudos. 
Contrato social - estado de natureza - pax capitalis - educação em rede MOSQUERA, Carlos Riádigos. El contrato social de la pax capitalis: la necesidad de un juicio educativo en red. RBEP, Brasília, DF, v. 95, n. 241, p. 482-496, set./dez. 2014. Seção: Estudos.

\section{Coordenador pedagógico}

MIZIARA, Leni Aparecida Souto; RIBEIRO, Ricardo; BEZERRA, Giovani Ferreira. O que revelam as pesquisas sobre a atuação do coordenador pedagógico. RBEP, Brasília, DF, v. 95, n. 241, p. 609-635, set./dez. 2014. Seção: Estudos.

Currículo - ensino de história - ensino médio

PEREIRA, Nilton Mullet et al. Docência em História: implicações das novas disposições curriculares do ensino médio. RBEP, Brasília, DF, v. 95, n. 239, p. 152-174, jan./abr. 2014. Seção: Estudos.

Currículo - formação de professores - ensino superior - língua Portuguesa

PENIN, Sonia T. S.; GALIAN, Cláudia V. A.; VALDEMARIN, Vera. Currículos de formação de professores de língua portuguesa: instituições autônomas e o poder de sua história. RBEP, Brasília, DF, v. 95, n. 239, p. 55-72, jan./ abr. 2014. Seção: Estudos.

Currículo - lazer - curso técnico - formação profissional

SANTOS, Carla Augusta Nogueira Lima e; ISAYAMA, Hélder Ferreira. O currículo de cursos técnicos de lazer no Brasil: um estudo de caso da formação profissional. RBEP, Brasília, DF, v. 95, n. 240, p. 276-303, mar./ ago. 2014. Seção: Estudos.

Defasagem idade-série - ensino médio - Rio Grande do Sul (RS) FRITSCH, Rosangela; VITELLI, Ricardo; ROCHA, Cleonice Silveira. Defasagem idade-série em escolas estaduais de ensino médio do Rio Grande do Sul. RBEP, Brasília, DF, v. 95, n. 239, p. 218-236, jan./abr. 2014. Seção: Estudos.

Desempenho acadêmico - acesso ao ensino superior - intervenção pedagógica

FAGUNDES, Caterine Vila. Percepção dos estudantes universitários acerca do acesso à educação superior: um estudo exploratório. RBEP, Brasília, DF, v. 95, n. 241, p. 508-525, set./dez. 2014. Seção: Estudos.

Dinâmicas de grupo - teoria da atividade - educação profissional ALBERTI, Taís Fim et al. Dinâmicas de grupo orientadas pelas atividades de estudo: desenvolvimento de habilidades e competências na educação profissional. RBEP, Brasília, DF, v. 95, n. 240, p. 346-362, maio/ago. 2014. Seção: Estudos.

Direitos humanos - educação - escola-conflitos

ZLUHAN, Mara Regina; RAITZ, Tânia Regina. A educação em direitos humanos para amenizar os conflitos no cotidiano das escolas. RBEP, Brasília, DF, v. 95, n. 239, p. 31-54, jan./abr. 2014. Seção: Estudos. 


\section{Docência - monitoria - ensino superior}

DANTAS, Otilia Maria. Monitoria: fonte de saberes à docência superior. RBEP, Brasília, DF, v. 95, n. 241, p. 567-589, set./dez. 2014. Seção: Estudos

\section{Edgar Morin}

MARTINAZZO, Celso José; DRESCH, Óberson Isac. Gênese das leis e dos princípios da teoria da complexidade em Edgar Morin. RBEP, Brasília, DF, v. 95, n. 240, p. 457-461. Seção: Resenhas.

Educação básica - ensino de Língua Portuguesa - atuação docente MAGALHAES, Tânia Guedes; CYRANKA, Lucia Furtado de Mendonça. Sujeito, educação e o trabalho com a Língua Portuguesa na escola básica. RBEP, Brasília, DF, v. 95, n. 241, p. 662-675, set./dez. 2014. Seção: Estudos.

Educação em rede - estado de natureza - pax capitalis - contrato social MOSQUERA, Carlos Riádigos. El contrato social de la pax capitalis: la necesidad de un juicio educativo en red. RBEP, Brasília, DF, v. 95, n. 241, p. 481-496, set./dez. 2014. Seção: Estudos.

\section{Educação integral - ensino fundamental - ludicidade}

AZEVEDO, Nair Correia Salgado; BETTI, Mauro. Escola de tempo integral e ludicidade: os pontos de vista de alunos do $1^{\circ}$ ano do ensino fundamental. RBEP, Brasília, DF, v. 95, n. 240, p. 255-275, maio/ago. 2014. Seção: Estudos.

\section{Educação matemática - Programa Pró-Letramento em Matemática}

GIUSTI, Neura Maria De Rossi; JUSTO, Jutta Cornelia Reuwsaat. Contribuições de uma experiência sobre o conteúdo de Tratamento da Informação no programa Pró-Letramento em Matemática. RBEP, Brasília, DF, v. 95, n. 241, p. 636-661, set./dez. 2014. Seção: Estudos.

Educação no campo - prática pedagógica - perfil docente - escola pública

PARENTE, Cláudia da Mota Darós. Perfil, concepções e práticas pedagógicas de professores que atuam em turmas multisseriadas de escolas públicas de Sergipe. RBEP, Brasília, DF, v. 95, n. 241, p. 676-695, set./dez. 2014. Seção: Estudos.

\section{Educação profissional - dinâmica de grupo - Teoria das atividades}

ALBERTI, Taís Fim et al. Dinâmicas de grupo orientadas pelas atividades de estudo: desenvolvimento de habilidades e competências na educação profissional. RBEP, Brasília, DF, v. 95, n. 240, p. 346-362, maio/ago. 2014. Seção: Estudos.

\section{Ensino colaborativo - inclusão escolar - prática docente}

VILARONGA, Carla Ariela Rios; MENDES, Enicéia Gonçalves. Ensino colaborativo para o apoio à inclusão escolar: práticas colaborativas entre os professores. RBEP, Brasília, DF, v. 95, n. 239, p. 139-151, jan./abr. 2014. Seção: Estudos. 
Ensino de Educação Física - formação de professores - transposição didática

MARTINY, Luis Eugênio; GOMES-DA-SILVA, Pierre Normando. A transposição didática na educação física escolar: o caminho formativo dos professores em formação inicial. RBEP, Brasília, DF, v. 95, n. 239, p. 175196, jan./abr. 2014. Seção: Estudos.

\section{Ensino de História - ensino médio - currículo}

PEREIRA, Nilton Mullet et al. Docência em História: implicações das novas disposições curriculares do ensino médio. RBEP, Brasília, DF, v. 95, n. 239, p. 152-174, jan./abr. 2014. Seção: Estudos.

Ensino de Língua Portuguesa - educação básica - atuação docente MAGALHÃES, Tânia Guedes; CYRANKA, Lucia Furtado de Mendonça. Sujeito, educação e o trabalho com a Língua Portuguesa na escola básica. RBEP, Brasília, DF, v. 95, n. 241, p. 662-675, set./dez. 2014. Seção: Estudos.

Ensino de Matemática - classe multisseriada - Amazônia

OLIVEIRA, José Sávio Bicho de; LUCENA, Isabel Cristina Rodrigues de. Alfabetização matemática em classes multisseriadas de escolas ribeirinhas da Amazônia: atuação docente em foco. RBEP, Brasília, DF, v. 95, n. 239, p. 87-111, jan./abr. 2014. Seção: Estudos.

Ensino de matemática - classe multisseriada - escola ribeirinha - Amazônia

OLIVEIRA, José Sávio Bicho de; LUCENA, Isabel Cristina Rodrigues de. Alfabetização matemática em classes multisseriadas de escolas ribeirinhas da Amazônia: atuação docente em foco. RBEP, Brasília, DF, v. 95, n. 239, p. 87-111, jan./abr. 2014. Seção: Estudos.

Ensino de matemática - formação continuada - Programa Próletramento em Matemática - tratamento da informação

GIUSTI, Neura Maria De Rossi; JUSTO, Jutta Cornelia Reuwsaat. Contribuições de uma experiência sobre o conteúdo de Tratamento da Informação no programa Pró-Letramento em Matemática. RBEP, Brasília, DF, v. 95, n. 241, p. 636-661, set./dez. 2014. Seção: Estudos.

\section{Ensino fundamental - educação integral - ludicidade}

AZEVEDO, Nair Correia Salgado; BETTI, Mauro. Escola de tempo integral e ludicidade: os pontos de vista de alunos do $1^{\circ}$ ano do ensino fundamental. RBEP, Brasília, DF, v. 95, n. 240, p. 255-275, maio/ago. 2014. Seção: Estudos.

Ensino médio - acesso ao ensino superior - políticas públicas em educação

CARMO, Erinaldo Ferreira et al. Políticas públicas de democratização do acesso ao ensino superior e estrutura básica de formação no ensino médio regular. RBEP, Brasília, DF, v. 95, n. 240, p. 304-327, maio/ago. 2014. Seção: Estudos. 


\section{Ensino médio - ensino de história - currículo}

PEREIRA, Nilton Mullet et al. Docência em História: implicações das novas disposições curriculares do ensino médio. RBEP, Brasília, DF, v. 95, n. 239, p. 152-174, jan./abr. 2014. Seção: Estudos.

Ensino médio - política educacional - defasagem idade-série - Rio Grande do Sul (RS)

FRITSCH, Rosangela; VITELLI, Ricardo; ROCHA, Cleonice Silveira. Defasagem idade-série em escolas estaduais de ensino médio do Rio Grande do Sul. RBEP, Brasília, DF, v. 95, n. 239, p. 218-236, jan./abr. 2014. Seção: Estudos.

\section{Ensino superior - aprendizagem - estilos de aprendizagem}

BARROS, Rita. MONTEIRO, Angélica Reis; MOREIRA, J. António Marques. Aprender no ensino superior: relações com a predisposição dos estudantes para o envolvimento na aprendizagem ao longo da vida. RBEP, Brasília, DF, v. 95, n. 241, p. 544-566, set./dez. 2014. Seção: Estudos.

\section{Ensino superior - docência - monitoria}

DANTAS, Otilia Maria. Monitoria: fonte de saberes à docência superior. RBEP, Brasília, DF, v. 95, n. 241, p. 567-589, set./dez. 2014. Seção: Estudos.

Ensino superior - inclusão educacional - antropologia educacional SILVA, Jefferson Olivatto da. Ações inclusivas no ensino superior brasileiro. RBEP, Brasília, DF, v. 95, n. 240, p. 414-430, maio/ago. 2014. Seção: Estudos.

Ensino superior - língua portuguesa - currículo - formação de professores

PENIN, Sonia T. S.; GALIAN, Cláudia V. A.; VALDEMARIN, Vera. Currículos de formação de professores de língua portuguesa: instituições autônomas e o poder de sua história. RBEP, Brasília, DF, v. 95, n. 239, p. 55-72, jan./ abr. 2014. Seção: Estudos.

\section{Ensino técnico - currículo - lazer - formação profissional}

SANTOS, Carla Augusta Nogueira Lima e; ISAYAMA, Hélder Ferreira. O currículo de cursos técnicos de lazer no Brasil: um estudo de caso da formação profissional. RBEP, Brasília, DF, v. 95, n. 240, p. 276-303, maio./ ago. 2014. Seção: Estudos.

Escola pública - educação no campo - prática pedagógica - perfil docente

PARENTE, Cláudia da Mota Darós. Perfil, concepções e práticas pedagógicas de professores que atuam em turmas multisseriadas de escolas públicas de Sergipe. RBEP, Brasília, DF, v. 95, n. 241, p. 676-695, set./dez. 2014. Seção: Estudos.

Escola ribeirinha - Amazônia - ensino de matemática - classe multisseriada - atuação docente

OLIVEIRA, José Sávio Bicho de; LUCENA, Isabel Cristina Rodrigues de. Alfabetização matemática em classes multisseriadas de escolas ribeirinhas 
da Amazônia: atuação docente em foco. RBEP, Brasília, DF, v. 95, n. 239, p. 87-111, jan./abr. 2014. Seção: Estudos.

Escola-conflitos - direitos humanos - educação

ZLUHAN, Mara Regina; RAITZ, Tânia Regina. A educação em direitos humanos para amenizar os conflitos no cotidiano das escolas. RBEP, Brasília, DF, v. 95, n. 239, p. 31-54, jan./abr. 2014. Seção: Estudos.

Estado de natureza - educação em rede - pax capitalis - contrato social MOSQUERA, Carlos. Riádigos. El contrato social de la pax capitalis: la necesidad de un juicio educativo en red. RBEP, Brasília, DF, v. 95, n. 241, p. 481-496, set./dez. 2014. Seção: Estudos.

Estilos de aprendizagem - ensino superior - aprendizagem

BARROS, Rita. MONTEIRO, Angélica Reis; MOREIRA, J. António Marques. Aprender no ensino superior: relações com a predisposição dos estudantes para o envolvimento na aprendizagem ao longo da vida. RBEP, Brasília, DF, v. 95, n. 241, p. 544-566, set./dez. 2014. Seção: Estudos.

Estoicismo - ceticismo - fundamentação da educação - Michel de Montaigne

BATISTA, Gustavo Araújo. Montaigne: a fundamentação da educação nos moldes céticos e estoicos. RBEP, Brasília, DF, v. 95, n. 241, p. 497-507, set./ dez. 2014. Seção: Estudos.

Financiamento da educação básica - transporte escolar - recurso federal

RIBEIRO, Andreia Couto; JESUS, Wellington Ferreira de. A evolução dos recursos federais nos programas de transporte escolar: impactos na educação básica. RBEP, Brasília, DF, v. 95, n. 241, p. 696-710, set./dez. 2014. Seção:

Formação acadêmica - acesso ao ensino superior - Programa Universidade para todos (ProUni)

FELICETTI, Vera Lucia. Comprometimento do aluno ProUni: acesso, persistência e formação acadêmica. RBEP, Brasília, DF, v. 95, n. 241, p. 526-543, set./dez. 2014. Seção: Estudos.

Formação continuada - ensino de matemática - Programa Próletramento em Matemática - formação continuada

GIUSTI, Neura Maria De Rossi; JUSTO, Jutta Cornelia Reuwsaat. Contribuições de uma experiência sobre o conteúdo de Tratamento da Informação no programa Pró-Letramento em Matemática. RBEP, Brasília, DF, v. 95, n. 241, p. 636-661, set./dez. 2014. Seção: Estudos.

\section{Formação de professores - ensino colaborativo}

VILARONGA, Carla Ariela Rios; MENDES, Enicéia Gonçalves. Ensino colaborativo para o apoio à inclusão escolar: práticas colaborativas entre os professores. RBEP, Brasília, DF, v. 95, n. 239, p. 139-151, jan./abr. 2014. Seção: Estudos. 
Formação de professores - ensino de Educação Física - transposição didática

MARTINY, Luis Eugênio; GOMES-DA-SILVA, Pierre Normando. A transposição didática na educação física escolar: o caminho formativo dos professores em formação inicial. RBEP, Brasília, DF, v. 95, n. 239, p. 175196, jan./abr. 2014. Seção: Estudos.

Formação de professores - ensino superior - língua portuguesa - currículo

PENIN, Sonia T. S.; GALIAN, Cláudia V. A.; VALDEMARIN, Vera. Currículos de formação de professores de língua portuguesa: instituições autônomas e o poder de sua história. RBEP, Brasília, DF, v. 95, n. 239, p. 55-72, jan./ abr. 2014. Seção: Estudos.

Formação de professores - ensino superior

DANTAS, Otilia Maria. Monitoria: fonte de saberes à docência superior. RBEP, Brasília, DF, v. 95, n. 241, p. 567-589, set./dez. 2014. Seção: Estudos.

\section{Formação de professores - manuais de ensino - modelos escolares}

KULESZA, Wojciech Andrzej. História da pedagogia no Brasil: a contribuição das pesquisas centradas em manuais de ensino. RBEP, Brasília, DF, v. 95, n. 240, p. 328-345, maio/ago. 2014. Seção: Estudos.

\section{Formação de professores - prática docente}

ALBUQUERQUE, Mayra Prates; FRISON, Lourdes Maria Bragagnolo; PORTO, Gilceane Caetano. Memorial de formação escrito no decorrer da prática docente: aprendizagens sobre alfabetização e letramento. RBEP, Brasília, DF, v. 95, n. 239, p. 73-86, jan./abr. 2014. Seção: Estudos

MIZIARA, Leni Aparecida Souto; RIBEIRO, Ricardo; BEZERRA, Giovani Ferreira. O que revelam as pesquisas sobre a atuação do coordenador pedagógico. RBEP, Brasília, DF, v. 95, n. 241, p. 609-635, set./dez. 2014. Seção: Estudos.

Formação profissional - ensino técnico - currículo - lazer

SANTOS, Carla Augusta Nogueira Lima e; ISAYAMA, Hélder Ferreira. O currículo de cursos técnicos de lazer no Brasil: um estudo de caso da formação profissional. RBEP, Brasília, DF, v. 95, n. 240, p. 276-303, maio/ ago. 2014. Seção: Estudos.

\section{Fundamentação da educação - ceticismo - estoicismo - Michel de Montaigne}

BATISTA, Gustavo Araújo. Montaigne: a fundamentação da educação nos moldes céticos e estoicos. RBEP, Brasília, DF, v. 95, n. 241, p. 497-507, set./ dez. 2014. Seção: Estudos.

\section{Inclusão educacional - ensino superior - antropologia educacional}

SILVA, Jefferson Olivatto da. Ações inclusivas no ensino superior brasileiro. RBEP, Brasília, DF, v. 95, n. 240, p. 414-430, maio/ago. 2014. Seção: Estudos. 
Inclusão escolar - ensino colaborativo - prática docente

VILARONGA, Carla Ariela Rios; MENDES, Enicéia Gonçalves. Ensino colaborativo para o apoio à inclusão escolar: práticas colaborativas entre os professores. RBEP, Brasília, DF, v. 95, n. 239, p. 139-151, jan./abr. 2014. Seção: Estudos.

Intervenção pedagógica - desempenho acadêmico - acesso ao ensino superior

FAGUNDES, Caterine Vila. Percepção dos estudantes universitários acerca do acesso à educação superior: um estudo exploratório. RBEP, Brasília, DF, v. 95, n. 241, p. 508-525, set./dez. 2014. Seção: Estudos.

Intervenção pedagógica - jogo de regras - Set Game - Londrina (PR) CARVALHO, Luciana Ramos Rodrigues de; OLIVEIRA, Francismara Neves de. Quando o jogo na escola é bem mais que jogo: possibilidades de intervenção pedagógica no jogo de regras Set Game. RBEP, Brasília, DF, v. 95, n. 240, p. 431-455, maio/ago. 2014. Seção: Estudos.

\section{Jean Piaget}

CARVALHO, Luciana Ramos Rodrigues de; OLIVEIRA, Francismara Neves de. Quando o jogo na escola é bem mais que jogo: possibilidades de intervenção pedagógica no jogo de regras Set Game. RBEP, Brasília, DF, v. 95, n. 240, p. 431-455, maio/ago. 2014. Seção: Estudos.

Jogo de regras - Set Game - intervenção pedagógica - Londrina (PR) CARVALHO, Luciana Ramos Rodrigues de; OLIVEIRA, Francismara Neves de. Quando o jogo na escola é bem mais que jogo: possibilidades de intervenção pedagógica no jogo de regras Set Game. RBEP, Brasília, DF, v. 95, n. 240, p. 431-455, maio/ago. 2014. Seção: Estudos.

\section{John Dewey}

CORREA, Rômulo Ferreira; MATOS, José Claudio. O crescimento da liberdade como fim educacional: a relação entre o pensamento reflexivo e a liberdade na obra de John Dewey. RBEP, Brasília, DF, v. 95, n. 239, p. 11-30, jan./abr. 2014. Seção: Estudos.

\section{Jornada de trabalho - docente}

ARELARO, Lisete Regina Gomes et al. Condições do trabalho docente: uma análise da carreira na rede municipal de ensino de São Paulo. RBEP, Brasília, DF, v. 95, n. 239, p. 197-217, jan./abr. 2014. Seção: Estudos.

Jornada de trabalho docente - plano de carreira - valorização do magistério - São Paulo (SP)

ARELARO, Lisete Regina Gomes et al. Condições do trabalho docente: uma análise da carreira na rede municipal de ensino de São Paulo. RBEP, Brasília, DF, v. 95, n. 239, p. 197-217, jan./abr. 2014. Seção: Estudos.

Lazer - currículo - ensino técnico - formação profissional

SANTOS, Carla Augusta Nogueira Lima e; ISAYAMA, Hélder Ferreira. O currículo de cursos técnicos de lazer no Brasil: um estudo de caso da 
formação profissional. RBEP, Brasília, DF, v. 95, n. 240, p. 276-303, maio/ ago. 2014. Seção: Estudos.

\section{Letramento - educação matemática - Programa Pró-Letramento em Matemática}

GIUSTI, Neura Maria de Rossi; JUSTO, Jutta Cornelia Reuwsaat. Contribuições de uma experiência sobre o conteúdo de Tratamento da Informação no programa Pró-Letramento em Matemática. RBEP, Brasília, DF, v. 95, n. 241, p. 636-661, set./dez. 2014. Seção: Estudos.

\section{Liberdade - John Dewey}

CORREA, Rômulo Ferreira; MATOS, José Claudio. O crescimento da liberdade como fim educacional: a relação entre o pensamento reflexivo e a liberdade na obra de John Dewey. RBEP, Brasília, DF, v. 95, n. 239, p. 11-30, jan./abr. 2014. Seção: Estudos.

Língua portuguesa - currículo - formação de professores - ensino superior

PENIN, Sonia T. S.; GALIAN, Cláudia V. A.; VALDEMARIN, Vera. Currículos de formação de professores de língua portuguesa: instituições autônomas e o poder de sua história. RBEP, Brasília, DF, v. 95, n. 239, p. 55-72, jan./ abr. 2014. Seção: Estudos.

\section{Ludicidade - ensino fundamental - educação integral}

AZEVEDO, Nair Correia Salgado; BETTI, Mauro. Escola de tempo integral e ludicidade: os pontos de vista de alunos do $1^{\circ}$ ano do ensino fundamental. RBEP, Brasília, DF, v. 95, n. 240, p. 255-275, maio/ago. 2014. Seção: Estudos.

\section{Manuais de ensino - modelos escolares - formação de professores}

KULESZA, Wojciech Andrzej. História da pedagogia no Brasil: a contribuição das pesquisas centradas em manuais de ensino. RBEP, Brasília, DF, v. 95, n. 240, p. 328-345, maio/ago. 2014. Seção: Estudos.

\section{Michel de Montaigne}

BATISTA, Gustavo Araújo. Montaigne: a fundamentação da educação nos moldes céticos e estoicos. RBEP, Brasília, DF, v. 95, n. 241, p. 497-507, set./ dez. 2014. Seção: Estudos.

\section{Modas educacionais}

CESTARI, Luiz Artur Santos. Esboço de uma compreensão da circulação de ideias: orientações para um estudo das modas educacionais. RBEP, Brasília, DF, v. 95, n. 240, p. 363-384, maio/ago. 2014. Seção: Estudos.

\section{Modelos escolares - manuais de ensino - formação de professores}

KULESZA, Wojciech Andrzej. História da pedagogia no Brasil: a contribuição das pesquisas centradas em manuais de ensino. RBEP, Brasília, DF, v. 95, n. 240, p. 328-345, maio/ago. 2014. Seção: Estudos.

\section{Monitoria - docência - ensino superior}

DANTAS, Otilia Maria. Monitoria: fonte de saberes à docência superior. RBEP, Brasília, DF, v. 95, n. 241, p. 567-589, set./dez. 2014. Seção: Estudos. 
Pax capitalis - contrato social - estado de natureza - educação em rede MOSQUERA, Carlos. Riádigos. El contrato social de la pax capitalis: la necesidad de un juicio educativo en red. RBEP, Brasília, DF, v. 95, n. 241, p. 481-496, set./dez. 2014. Seção: Estudos.

\section{Pensamento reflexivo - John Dewey}

CORREA, Rômulo Ferreira; MATOS, José Claudio. O crescimento da liberdade como fim educacional: a relação entre o pensamento reflexivo e a liberdade na obra de John Dewey. RBEP, Brasília, DF, v. 95, n. 239, p. 11-30, jan./abr. 2014. Seção: Estudos.

Perfil do docente - prática docente - professor

EUGENIA VICENTE, María. Profesores de educación: perfiles y prácticas profesionales. RBEP, Brasília, DF, v. 95, n. 241, p. 590-608, set./dez. 2014. Seção: Estudos.

Perfil docente - escola pública - educação no campo - prática pedagógica

PARENTE, Cláudia da Mota Darós. Perfil, concepções e práticas pedagógicas de professores que atuam em turmas multisseriadas de escolas públicas de Sergipe. RBEP, Brasília, DF, v. 95, n. 241, p. 590-608, set./dez. 2014. Seção: Estudos.

Pesquisa - docência - ensino superior

PEREIRA, Nilton Mullet et al. Docência em História: implicações das novas disposições curriculares do ensino médio. RBEP, Brasília, DF, v. 95, n. 239, p. 152-174, jan./abr. 2014. Seção: Estudos.

\section{Pesquisa-ação - ensino superior}

SILVA, Jefferson Olivatto da. Ações inclusivas no ensino superior brasileiro. RBEP, Brasília, DF, v. 95, n. 240, p. 414-430, maio/ago. 2014. Seção: Estudos.

Plano de carreira - jornada de trabalho docente - valorização do magistério - São Paulo (SP)

ARELARO, Lisete Regina Gomes et al. Condições do trabalho docente: uma análise da carreira na rede municipal de ensino de São Paulo. RBEP, Brasília, DF, v. 95, n. 239, p. 197-217, jan./abr. 2014. Seção: Estudos.

\section{Política educacional - acesso à educação superior}

CARMO, Erinaldo Ferreira et al. Políticas públicas de democratização do acesso ao ensino superior e estrutura básica de formação no ensino médio regular. RBEP, Brasília, DF, v. 95, n. 240, p. 304-327, maio/ago. 2014. Seção: Estudos.

Política educacional - escola estadual - ensino médio - Rio Grande do Sul - defasagem idade-série FRITSCH, Rosangela; VITELLI, Ricardo; ROCHA, Cleonice Silveira. Defasagem idade-série em escolas estaduais de ensino médio do Rio Grande do Sul. RBEP, Brasília, DF, v. 95, n. 239, p. 218-236, jan./abr. 2014. Seção: Estudos. 
Políticas públicas da educação - Bataguassu - Mato Grosso do Sul (MS) - Programa Nacional de Tecnologia Educacional

ZANDAVALLI, Carla Busato; PEDROSA, Dirceu Martins. Implantação e implementação do Proinfo no município de Bataguassu, Mato Grosso do Sul: o olhar dos profissionais da educação. RBEP, Brasília, DF, v. 95, n. 240, p. 385-413, maio/ago. 2014. Seção: Estudos.

Políticas públicas em educação - acesso ao ensino superior - ensino médio

CARMO, Erinaldo Ferreira et al. Políticas públicas de democratização do acesso ao ensino superior e estrutura básica de formação no ensino médio regular. RBEP, Brasília, DF, v. 95, n. 240, p. 304-327, maio/ago. 2014. Seção: Estudos.

Prática docente - inclusão escolar - ensino colaborativo

VILARONGA, Carla Ariela Rios; MENDES, Enicéia Gonçalves. Ensino colaborativo para o apoio à inclusão escolar: práticas colaborativas entre os professores. RBEP, Brasília, DF, v. 95, n. 239, p. 139-151, jan./abr. 2014. Seção: Estudos.

Prática docente - perfil do docente - professor

EUGENIA VICENTE, María. Profesores de educación: perfiles y prácticas profesionales. RBEP, Brasília, DF, v. 95, n. 241, p. 590-608, set./dez. 2014. Seção: Estudos.

Prática docente - Programa de Iniciação à Docência

AlBUQUERQUE, Mayra Prates; FRISON, Lourdes Maria Bragagnolo; PORTO, Gilceane Caetano. Memorial de formação escrito no decorrer da prática docente: aprendizagens sobre alfabetização e letramento. RBEP, Brasília, DF, v. 95, n. 239, p. 73-86, jan./abr. 2014. Seção: Estudos.

Prática pedagógica - escola pública - educação no campo - perfil docente

PARENTE, Cláudia da Mota Darós. Perfil, concepções e práticas pedagógicas de professores que atuam em turmas multisseriadas de escolas públicas de Sergipe. RBEP, Brasília, DF, v. 95, n. 241, p. 676-695, set./dez. 2014. Seção: Estudos.

\section{Professor - perfil do docente - prática docente}

EUGENIA VICENTE, María. Profesores de educación: perfiles y prácticas profesionales. RBEP, Brasília, DF, v. 95, n. 241, p. 590-608, set./dez. 2014. Seção: Estudos.

Programa de Iniciação à Docência - prática docente ALBUQUERQUE, Mayra Prates; FRISON, Lourdes Maria Bragagnolo; PORTO, Gilceane Caetano. Memorial de formação escrito no decorrer da prática docente: aprendizagens sobre alfabetização e letramento. RBEP, Brasília, DF, v. 95, n. 239, p. 73-86, jan./abr. 2014. Seção: Estudos. 
Programa Nacional de Tecnologia Educacional - profissional da educação - Bataguassu - Mato Grosso do Sul (MS)

ZANDAVALLI, Carla Busato; PEDROSA, Dirceu Martins. Implantação e implementação do Proinfo no município de Bataguassu, Mato Grosso do Sul: o olhar dos profissionais da educação. RBEP, Brasília, DF, v. 95, n. 240, p. 385-413, maio/ago. 2014. Seção: Estudos.

\section{Programa Pró-Letramento em Matemática}

GIUSTI, Neura Maria De Rossi; JUSTO, Jutta Cornelia Reuwsaat. Contribuições de uma experiência sobre o conteúdo de Tratamento da Informação no programa Pró-Letramento em Matemática. RBEP, Brasília, DF, v. 95, n. 241, p. 636-661, set./dez. 2014. Seção: Estudos.

Programa Universidade para todos (ProUni) - Formação acadêmica acesso ao ensino superior

FELICETTI, Vera Lucia. Comprometimento do aluno ProUni: acesso, persistência e formação acadêmica. $R B E P$, Brasília, DF, v. 95, n. 241, p. 526543, set./dez. 2014. Seção: Estudos.

Psicomotricidade - aprendizagem - ensino de matemática FERNANDES, Cleonice Terezinha; DANTAS, Paulo Moreira Silva; MOURÃOCARVALHAL, Maria Isabel. Desempenho psicomotor de escolares com dificuldades de aprendizagem em cálculos. RBEP, Brasília, DF, v. 95, n. 239, p. 112-138, jan./abr. 2014. Seção: Estudos.

\section{Rede Estadual de Ensino - política educacional}

PEDROSA, Dirceu Martins. Implantação e implementação do Proinfo no município de Bataguassu, Mato Grosso do Sul: o olhar dos profissionais da educação. RBEP, Brasília, DF, v. 95, n. 240, p. 385-413, mar./ago. 2014. Seção: Estudos.

Remuneração docente - escola municipal - São Paulo (SP)

ARELARO, Lisete Regina Gomes et al. Condições do trabalho docente: uma análise da carreira na rede municipal de ensino de São Paulo. RBEP, Brasília, DF, v. 95, n. 239, p. 197-217, jan./abr. 2014. Seção: Estudos.

Set Game - jogo de regras - intervenção pedagógica - Londrina (PR) CARVALHO, Luciana Ramos Rodrigues de; OLIVEIRA, Francismara Neves de. Quando o jogo na escola é bem mais que jogo: possibilidades de intervenção pedagógica no jogo de regras Set Game. RBEP, Brasília, DF, v. 95, n. 240, p. 431-455, maio/ago. 2014. Seção: Estudos.

Teoria da atividade - educação profissional - dinâmicas de grupo ALBERTI, Taís Fim et al. Dinâmicas de grupo orientadas pelas atividades de estudo: desenvolvimento de habilidades e competências na educação profissional. RBEP, Brasília, DF, v. 95, n. 240, p. 346-362, maio/ago. 2014. Seção: Estudos. 
Transporte escolar - financiamento da educação básica - Recurso federal

RIBEIRO, Andreia Couto; JESUS, Wellington Ferreira de. A evolução dos recursos federais nos programas de transporte escolar: impactos na educação básica. RBEP, Brasília, DF, v. 95, n. 241, p. 694-710, set./dez. 2014. Seção: Estudos.

Transposição didática - formação de professores - ensino de educação física

MARTINY, Luis Eugênio; GOMES-DA-SILVA, Pierre Normando. A transposição didática na educação física escolar: o caminho formativo dos professores em formação inicial. RBEP, Brasília, DF, v. 95, n. 239, p. 175196, jan./abr. 2014. Seção: Estudos.

Tratamento da informação - Programa Pró-Letramento em Matemática - ensino de matemática - formação continuada

GIUSTI, Neura Maria De Rossi; JUSTO, Jutta Cornelia Reuwsaat. Contribuições de uma experiência sobre o conteúdo de Tratamento da Informação no programa Pró-Letramento em Matemática. RBEP, Brasília, DF, v. 95, n. 241, p. 636-661, set./dez. 2014. Seção: Estudos.

Valorização do magistério - São Paulo (SP) - plano de carreira - jornada de trabalho docente

ARELARO, Lisete Regina Gomes et al. Condições do trabalho docente: uma análise da carreira na rede municipal de ensino de São Paulo. RBEP, Brasília, DF, v. 95, n. 239, p. 197-217, jan./abr. 2014. Seção: Estudos. 


\section{ÍNDICE DE AUTORES RBEP}

ABEGG, Ilse; COSTA, Márcia Rejane Julio; TITTON, Mauro; ALBERTI, Taís Fim. Dinâmicas de grupo orientadas pelas atividades de estudo: desenvolvimento de habilidades e competências na educação profissional. RBEP, Brasília, DF, v. 95, n. 240, p. 346-362, mar./ago. 2014. Seção: Estudos.

ALBERTI, Taís Fim; ABEGG, Ilse; COSTA, Márcia Rejane Julio; TITTON, Mauro. Dinâmicas de grupo orientadas pelas atividades de estudo: desenvolvimento de habilidades e competências na educação profissional. RBEP, Brasília, DF, v. 95, n. 240, p. 346-362, mar./ago. 2014. Seção: Estudos.

ALBUQUERQUE, Mayra Prates; FRISON, Lourdes Maria Bragagnolo; PORTO, Gilceane Caetano. Memorial de formação escrito no decorrer da prática docente: aprendizagens sobre alfabetização e letramento. RBEP, Brasília, DF, v. 95, n. 239, p. 73-86, jan./abr. 2014. Seção: Estudos.

ARELARO, Lisete Regina Gomes; JACOMINI, Márcia Aparecida; SOUZA, Nilson Alves de; SANTOS, Kátia Aparecida. Condições do trabalho docente: uma análise da carreira na rede municipal de ensino de São Paulo. RBEP, Brasília, DF, v. 95, n. 239, p. 199-217, jan./abr. 2014. Seção: Estudos.

AZEVEDO, Nair Correia Salgado; BETTI, Mauro. Escola de tempo integral e ludicidade: os pontos de vista de alunos do $1^{\circ}$ ano do ensino fundamental. RBEP, Brasília, DF, v. 95, n. 240, p. 255-275, mar./ago. 2014. Seção: Estudos. 
BARROS, Rita; MONTEIRO, Angélica Reis; MOREIRA, J. António Marques. Aprender no ensino superior: relações com a predisposição dos estudantes para o envolvimento na aprendizagem ao longo da vida. RBEP, Brasília, DF, v. 95, n. 241, p. 544-566, mar./ago. 2014. Seção: Estudos.

BATISTA, Gustavo Araújo. Montaigne: a fundamentação da educação nos moldes céticos e estoicos. RBEP, Brasília, DF, v. 95, n. 241, p. 497-507, mar./ago. 2014. Seção:

BETTI, Mauro; AZEVEDO, Nair Correia Salgado. Escola de tempo integral e ludicidade: os pontos de vista de alunos do $1^{\circ}$ ano do ensino fundamental. RBEP, Brasília, DF, v. 95, n. 240, p. 255-275, mar./ago. 2014. Seção: Estudos.

BEZERRA, Giovani Ferreira; MIZIARA, Leni Aparecida Souto; RIBEIRO, Ricardo. O que revelam as pesquisas sobre a atuação do coordenador pedagógico. RBEP, Brasília, DF, v. 95, n. 241, p. 609-635, mar./ago. 2014. Seção: Estudos

CARMO, Erinaldo Ferreira; CHAGAS, José Aercio Silva; FIGUEIREDO FILHO, Dalson Britto; ROCHA, Enivaldo Carvalho. Políticas públicas de democratização do acesso ao ensino superior e estrutura básica de formação no ensino médio regular. RBEP, Brasília, DF, v. 95, n. 240, p. 304-327, mar./ ago. 2014. Seção: Estudos.

CARVALHO, Luciana Ramos Rodrigues de; OLIVEIRA, Francismara Neves de. Quando o jogo na escola é bem mais que jogo: possibilidades de intervenção pedagógica no jogo de regras Set Game. RBEP, Brasília, DF, v. 95, n. 240, p. 431-455, mar./ago. 2014. Seção: Estudos.

CESTARI, Luiz Artur Santos. Esboço de uma compreensão da circulação de ideias: orientações para um estudo das modas educacionais. RBEP, Brasília, DF, v. 95, n. 240, p. 363-384, mar./ago. 2014. Seção: Estudos.

CHAGAS, José Aercio Silva; FIGUEIREDO FILHO, Dalson Britto; ROCHA, Enivaldo Carvalho; CARMO, Erinaldo Ferreira. Políticas públicas de democratização do acesso ao ensino superior e estrutura básica de formação no ensino médio regular. RBEP, Brasília, DF, v. 95, n. 240, p. 304-327, mar./ ago. 2014. Seção: Estudos.

CORREA, Rômulo Ferreira; MATOS, José Claudio. O crescimento da liberdade como fim educacional: a relação entre o pensamento reflexivo e a liberdade na obra de John Dewey. RBEP, Brasília, DF, v. 95, n. 239, p. 11-30, jan./abr. 2014. Seção: Estudos.

COSTA, Márcia Rejane Julio; TITTON, Mauro; ALBERTI, Taís Fim; ABEGG, Ilse; COSTA, Márcia Rejane Julio. Dinâmicas de grupo orientadas pelas atividades de estudo: desenvolvimento de habilidades e competências na educação profissional. RBEP, Brasília, DF, v. 95, n. 240, p. 346-362, mar./ ago. 2014. Seção: Estudos. 
CYRANKA, Lucia Furtado de Mendonça; MAGALHÃES, Tânia Guedes. Sujeito, educação e o trabalho com a Língua Portuguesa na escola básica. RBEP, Brasília, DF, v. 95, n. 241, p. 622-675, set./dez. 2014. Seção: Estudos.

DAGNONI, Janine Marinho. Cosiderações construtivistas sobre oportunidades vulnerabilidades na adolescência. RBEP, Brasília, DF, v. 95, n. 241, p. 711-716, set./dez. 2014. Seção: Estudos.

DANTAS, Otilia Maria. Monitoria: fonte de saberes à docência superior. RBEP, Brasília, DF, v. 95, n. 241, p. 567-589, set./dez. 2014. Seção: Estudos.

DANTAS, Paulo Moreira Silva; MOURÃO-CARVALHAL, Maria Isabel; FERNANDES, Cleonice Terezinha. Desempenho psicomotor de escolares com dificuldades de aprendizagem em cálculos. RBEP, Brasília, DF, v. 95, n. 239, p. 112-138, jan./abr. 2014. Seção: Estudos.

DRESCH, Óberson Isac; MARTINAZZO, Celso José. Gênese das leis e dos princípios da teoria da complexidade em Edgar Morin. RBEP, Brasília, DF, v. 95, n. 240, p. 457-461. Seção: Resenhas.

EUGENIA VICENTE, Maria. Profesores de educación: perfiles y prácticas profesionales. RBEP, Brasília, DF, v. 95, n. 241, p. 590-608, mar./ago. 2014. Seção: Estudos.

FAGUNDES, Caterine Vila. Percepção dos estudantes universitários acerca do acesso à educação superior: um estudo exploratório. RBEP, Brasília, DF, v. 95, n. 241, p. 508-525, set./dez. 2014. Seção: Estudos.

FELICETTI, Vera Lucia. Comprometimento do aluno ProUni: acesso, persistência e formação acadêmica. RBEP, Brasília, DF, v. 95, n. 241, p. 526-543, set./dez. 2014. Seção: Estudos.

FERNANDES, Cleonice Terezinha; DANTAS, Paulo Moreira Silva; MOURÃOCARVALHAL, Maria Isabel. Desempenho psicomotor de escolares com dificuldades de aprendizagem em cálculos. RBEP, Brasília, DF, v. 95, n. 239, p. 112-138, jan./abr. 2014. Seção: Estudos.

FIGUEIREDO FILHO, Dalson Britto; ROCHA, Enivaldo Carvalho; CARMO, Erinaldo Ferreira; CHAGAS, José Aercio Silva. Políticas públicas de democratização do acesso ao ensino superior e estrutura básica de formação no ensino médio regular. RBEP, Brasília, DF, v. 95, n. 240, p. 304-327, mar./ ago. 2014. Seção: Estudos.

FRISON, Lourdes Maria Bragagnolo; PORTO, Gilceane Caetano; ALBUQUERQUE, Mayra Prates. Memorial de formação escrito no decorrer da prática docente: aprendizagens sobre alfabetização e letramento. RBEP, Brasília, DF, v. 95, n. 239, p. 73-86, jan./abr. 2014. Seção: Estudos. 
FRITSCH, Rosangela; VITELLI, Ricardo; ROCHA, Cleonice Silveira. Defasagem idade-série em escolas estaduais de ensino médio do Rio Grande do Sul. RBEP, Brasília, DF, v. 95, n. 239, p. 219-236, jan./abr. 2014. Seção: Estudos.

GALIAN, Cláudia V. A. VALDEMARIN, Vera; PENIN, Sonia T. S. Currículos de formação de professores de língua portuguesa: instituições autônomas e o poder de sua história. RBEP, Brasília, DF, v. 95, n. 239, p. 55-72, jan./ abr. 2014. Seção: Estudos

GIL, Carmem Zeli; MEINERZ, Carla; PEREIRA, Nilton Mullet; SEFFNER, Fernando. Docência em História: implicações das novas disposições curriculares do ensino médio. RBEP, Brasília, DF, v. 95, n. 239, p. 152-174, jan./abr. 2014. Seção: Estudos.

GIUSTI, Neura Maria de Rossi; JUSTO, Jutta Cornelia Reuwsaat. Contribuições de uma experiência sobre o conteúdo de tratamento da informação no Programa Pró-Letramento em Matemática. RBEP, Brasília, DF, v. 95, n. 241, p. 636-661, set./dez. 2014. Seção: Estudos.

GOMES-DA-SILVA, Pierre Normando; MARTINY, Luis Eugênio. A transposição didática na educação física escolar: o caminho formativo dos professores em formação inicial. RBEP, Brasília, DF, v. 95, n. 239, p. 175198, jan./abr. 2014. Seção: Estudos.

ISAYAMA, Hélder Ferreira; SANTOS, Carla Augusta Nogueira Lima e. O currículo de cursos técnicos de lazer no Brasil: um estudo de caso da formação profissional. RBEP, Brasília, DF, v. 95, n. 240, p. 276-303, mar./ ago. 2014. Seção: Estudos.

JACOMINI, Márcia Aparecida; SOUZA, Nilson Alves de; SANTOS, Kátia Aparecida; ARELARO, Lisete Regina Gomes. Condições do trabalho docente: uma análise da carreira na rede municipal de ensino de São Paulo. RBEP, Brasília, DF, v. 95, n. 239, p. 199-217, jan./abr. 2014. Seção: Estudos.

JESUS, Wellington Ferreira de; RIBEIRO, Andreia Couto. A evolução dos recursos federais nos programas de transporte escolar: impactos na educação básica. RBEP, Brasília, DF, v. 95, n. 241, p. 696-710, set./dez. 2014. Seção: Estudos.

JUSTO, Jutta Cornelia Reuwsaat; GIUSTI, Neura Maria de Rossi. Contribuições de uma experiência sobre o conteúdo de tratamento da informação no Programa Pró-Letramento em Matemática. RBEP, Brasília, DF, v. 95, n. 241, p. 636-661, set./dez. 2014. Seção: Estudos.

KULESZA, Wojciech Andrzej. História da pedagogia no Brasil: a contribuição das pesquisas centradas em manuais de ensino. RBEP, Brasília, DF, v. 95, n. 240, p. 328-345, mar./ago. 2014. Seção: Estudos. 
LUCENA, Isabel Cristina Rodrigues de; OLIVEIRA, José Sávio Bicho de. Alfabetização matemática em classes multisseriadas de escolas ribeirinhas da Amazônia: atuação docente em foco. RBEP, Brasília, DF, v. 95, n. 239, p. 87-111, jan./abr. 2014. Seção: Estudos.

MAGALHÃES, Tânia Guedes; CYRANKA, Lucia Furtado de Mendonça. Sujeito, educação e o trabalho com a Língua Portuguesa na escola básica. RBEP, Brasília, DF, v. 95, n. 241, p. 662-675, set./dez. 2014. Seção: Estudos.

MARTINAZZO, Celso José; DRESCH, Óberson Isac. Gênese das leis e dos princípios da teoria da complexidade em Edgar Morin. RBEP, Brasília, DF, v. 95, n. 240, p. 457-461. Seção: Resenhas.

MARTINY, Luis Eugênio; GOMES-DA-SILVA, Pierre Normando. A transposição didática na educação física escolar: o caminho formativo dos professores em formação inicial. RBEP, Brasília, DF, v. 95, n. 239, p. 175198, jan./abr. 2014. Seção: Estudos.

MATOS, José Claudio; CORREA, Rômulo Ferreira. O crescimento da liberdade como fim educacional: a relação entre o pensamento reflexivo e a liberdade na obra de John Dewey. RBEP, Brasília, DF, v. 95, n. 239, p. 11-30, jan./abr. 2014. Seção: Estudos.

MEINERZ, Carla; PEREIRA, Nilton Mullet; SEFFNER, Fernando; GIL, Carmem Zeli. Docência em História: implicações das novas disposições curriculares do ensino médio. RBEP, Brasília, DF, v. 95, n. 239, p. 152-174, jan./abr. 2014. Seção: Estudos.

MENDES, Enicéia Gonçalves; VILARONGA, Carla Ariela Rios. Ensino colaborativo para o apoio à inclusão escolar: práticas colaborativas entre os professores. RBEP, Brasília, DF, v. 95, n. 239, p. 139-151, jan./abr. 2014. Seção: Estudos.

MIZIARA, Leni Aparecida Souto; RIBEIRO, Ricardo; BEZERRA, Giovani Ferreira. O que revelam as pesquisas sobre a atuação do coordenador pedagógico. RBEP, Brasília, DF, v. 95, n. 241, p. 609-635, set./dez. 2014. Seção: Estudos.

MONTEIRO, Angélica Reis; MOREIRA, J. António Marques; BARROS, Rita. Aprender no ensino superior: relações com a predisposição dos estudantes para o envolvimento na aprendizagem ao longo da vida. RBEP, Brasília, DF, v. 95, n. 241, p. 544-566, set./dez. 2014. Seção: Estudos.

MOREIRA, J. António Marques; BARROS, Rita. MONTEIRO, Angélica Reis. Aprender no ensino superior: relações com a predisposição dos estudantes para o envolvimento na aprendizagem ao longo da vida. RBEP, Brasília, DF, v. 95, n. 241, p. 544-566, set./dez. 2014. Seção: Estudos. 
MOSQUERA, Carlos Riádigos. El contrato Social de la pax capitalis: la necesidad de un juicio educativo en red. RBEP, Brasília, DF, v. 95, n. 241, p. 481-496, set./dez. 2014. Seção: Estudos.

MOURÃO-CARVALHAL, Maria Isabel; FERNANDES, Cleonice Terezinha; DANTAS, Paulo Moreira Silva. Desempenho psicomotor de escolares com dificuldades de aprendizagem em cálculos. RBEP, Brasília, DF, v. 95, n. 239, p. 112-138, jan./abr. 2014. Seção: Estudos.

OLIVEIRA, Francismara Neves de; CARVALHO, Luciana Ramos Rodrigues de. Quando o jogo na escola é bem mais que jogo: possibilidades de intervenção pedagógica no jogo de regras Set Game. RBEP, Brasília, DF, v. 95, n. 240, p. 431-455, mar./ago. 2014. Seção: Estudos.

OLIVEIRA, José Sávio Bicho de; LUCENA, Isabel Cristina Rodrigues de. Alfabetização matemática em classes multisseriadas de escolas ribeirinhas da Amazônia: atuação docente em foco. RBEP, Brasília, DF, v. 95, n. 239, p. 87-111, jan./abr. 2014. Seção: Estudos.

PARENTE, Cláudia da Mota Darós. Perfil, concepções e práticas pedagógicas de professores que atuam em turmas multisseriadas de escolas públicas de Sergipe. RBEP, Brasília, DF, v. 95, n. 241, p. 676-695, set./dez. 2014. Seção: Estudos.

PEDROSA, Dirceu Martins; ZANDAVALLI, Carla Busato. Implantação e implementação do Proinfo no município de Bataguassu, Mato Grosso do Sul: o olhar dos profissionais da educação. RBEP, Brasília, DF, v. 95, n. 240, p. 385-413, mar./ago. 2014. Seção: Estudos.

PENIN, Sonia T. S. GALIAN, Cláudia V. A. VALDEMARIN, Vera. Currículos de formação de professores de língua portuguesa: instituições autônomas e o poder de sua história. RBEP, Brasília, DF, v. 95, n. 239, p. 55-72, jan./ abr. 2014. Seção: Estudos.

PEREIRA, Nilton Mullet; SEFFNER, Fernando; GIL, Carmem Zeli; MEINERZ, Carla. Docência em História: implicações das novas disposições curriculares do ensino médio. RBEP, Brasília, DF, v. 95, n. 239, p. 152-174, jan./abr. 2014. Seção: Estudos.

PORTO, Gilceane Caetano; ALBUQUERQUE, Mayra Prates; FRISON, Lourdes Maria Bragagnolo. Memorial de formação escrito no decorrer da prática docente: aprendizagens sobre alfabetização e letramento. RBEP, Brasília, DF, v. 95, n. 239, p. 73-86, jan./abr. 2014. Seção: Estudos.

RAITZ, Tânia Regina; ZLUHAN, Mara Regina. A educação em direitos humanos para amenizar os conflitos no cotidiano das escolas. RBEP, Brasília, DF, v. 95, n. 239, p. 31-54, jan./abr. 2014. Seção: Estudos. 
RIBEIRO, Andreia Couto; JESUS, Wellington Ferreira de. A evolução dos recursos federais nos programas de transporte escolar: impactos na educação básica. RBEP, Brasília, DF, v. 95, n. 241, p. 696-710, set./dez. 2014. Seção: Estudos.

RIBEIRO, Ricardo; BEZERRA, Giovani Ferreira; MIZIARA, Leni Aparecida Souto. O que revelam as pesquisas sobre a atuação do coordenador pedagógico. RBEP, Brasília, DF, v. 95, n. 241, p. 609-635, set./dez. 2014. Seção: Estudos.

ROCHA, Cleonice Silveira; FRITSCH, Rosangela; VITELLI, Ricardo. Defasagem idade-série em escolas estaduais de ensino médio do Rio Grande do Sul. RBEP, Brasília, DF, v. 95, n. 239, p. 219-236, jan./abr. 2014. Seção: Estudos.

ROCHA, Enivaldo Carvalho, CARMO, Erinaldo Ferreira; CHAGAS, José Aercio Silva; FIGUEIREDO FILHO, Dalson Britto. Políticas públicas de democratização do acesso ao ensino superior e estrutura básica de formação no ensino médio regular. RBEP, Brasília, DF, v. 95, n. 240, p. 304-327, mar./ ago. 2014. Seção: Estudos.

SANTOS, Carla Augusta Nogueira Lima e; ISAYAMA, Hélder Ferreira. O currículo de cursos técnicos de lazer no Brasil: um estudo de caso da formação profissional. RBEP, Brasília, DF, v. 95, n. 240, p. 276-303, mar./ ago. 2014. Seção: Estudos.

SANTOS, Kátia Aparecida; ARELARO, Lisete Regina Gomes; JACOMINI, Márcia Aparecida; SOUZA, Nilson Alves de. Condições do trabalho docente: uma análise da carreira na rede municipal de ensino de São Paulo. RBEP, Brasília, DF, v. 95, n. 239, p. 199-217, jan./abr. 2014. Seção: Estudos.

SEFFNER, Fernando; GIL, Carmem Zeli; MEINERZ, Carla; PEREIRA, Nilton Mullet. Docência em História: implicações das novas disposições curriculares do ensino médio. RBEP, Brasília, DF, v. 95, n. 239, p. 152-174, jan./abr. 2014. Seção: Estudos.

SILVA, Jefferson Olivatto da. Ações inclusivas no ensino superior brasileiro. RBEP, Brasília, DF, v. 95, n. 240, p. 414-430, mar./ago. 2014. Seção: Estudos.

SOUZA, Nilson Alves de; SANTOS, Kátia Aparecida; ARELARO, Lisete Regina Gomes; JACOMINI, Márcia Aparecida. Condições do trabalho docente: uma análise da carreira na rede municipal de ensino de São Paulo. RBEP, Brasília, DF, v. 95, n. 239, p. 199-217, jan./abr. 2014. Seção: Estudos

TITTON, Mauro; ALBERTI, Taís Fim; ABEGG, Ilse; COSTA, Márcia Rejane Julio. Dinâmicas de grupo orientadas pelas atividades de estudo: desenvolvimento de habilidades e competências na educação profissional RBEP, Brasília, DF, v. 95, n. 240, p. 346-362, mar./ago. 2014. Seção: Estudos. 
VALDEMARIN, Vera; PENIN, Sonia T. S.; GALIAN, Cláudia V. A. Currículos de formação de professores de língua portuguesa: instituições autônomas e o poder de sua história. RBEP, Brasília, DF, v. 95, n. 239, p. 55-72, jan./ abr. 2014. Seção: Estudos.

VILARONGA, Carla Ariela Rios; MENDES, Enicéia Gonçalves. Ensino colaborativo para o apoio à inclusão escolar: práticas colaborativas entre os professores. RBEP, Brasília, DF, v. 95, n. 239, p. 139-151, jan./abr. 2014. Seção: Estudos.

VITELLI, Ricardo; ROCHA, Cleonice Silveira; FRITSCH, Rosangela. Defasagem idade-série em escolas estaduais de ensino médio do Rio Grande do Sul. RBEP, Brasília, DF, v. 95, n. 239, p. 219-236, jan./abr. 2014. Seção: Estudos.

ZANDAVALLI, Carla Busato; PEDROSA, Dirceu Martins. Implantação e implementação do Proinfo no município de Bataguassu, Mato Grosso do Sul: o olhar dos profissionais da educação. RBEP, Brasília, DF, v. 95, n. 240, p. 385-413, mar./ago. 2014. Seção: Estudos.

ZLUHAN, Mara Regina; RAITZ, Tânia Regina. A educação em direitos humanos para amenizar os conflitos no cotidiano das escolas. RBEP, Brasília, DF, v. 95, n. 239, p. 31-54, jan./abr. 2014. Seção: Estudos. 


\section{Índice de títulos RBEP}

Ações inclusivas no ensino superior brasileiro.

SILVA, Jefferson Olivatto da. Ações inclusivas no ensino superior brasileiro. RBEP, Brasília, DF, v. 95, n. 240, p. 414-430, maio/ago. 2014. Seção: Estudos.

Alfabetização matemática em classes multisseriadas de escolas ribeirinhas da Amazônia: atuação docente em foco.

OLIVEIRA, José Sávio Bicho de; LUCENA, Isabel Cristina Rodrigues de. Alfabetização matemática em classes multisseriadas de escolas ribeirinhas da Amazônia: atuação docente em foco. RBEP, Brasília, DF, v. 95, n. 239, p. 87-111, jan./abr. 2014. Seção: Estudos.

Aprender no ensino superior: relações com a predisposição dos estudantes para o envolvimento na aprendizagem ao longo da vida.

BARROS, Rita. MONTEIRO, Angélica Reis; MOREIRA, J. António Marques. Aprender no ensino superior: relações com a predisposição dos estudantes para o envolvimento na aprendizagem ao longo da vida. RBEP, Brasília, DF, v. 95, n. 241, p. 544-566, set./dez. 2014. Seção: Estudos.

Comprometimento do aluno ProUni: acesso, persistência e formação acadêmica.

FELICETTI, Vera Lucia. Comprometimento do aluno ProUni: acesso, persistência e formação acadêmica. RBEP, Brasília, DF, v. 95, n. 241, p. 526-543, set./dez. 2014. Seção: Estudos. 
Condições do trabalho docente: uma análise da carreira na rede municipal de ensino de São Paulo. ARELARO, Lisete Regina Gomes et al. Condições do trabalho docente: uma análise da carreira na rede municipal de ensino de São Paulo. RBEP, Brasília, DF, v. 95, n. 239, p. 199-217, jan./ abr. 2014. Seção: Estudos.

Considerações construtivistas sobre oportunidades vulnerabilidades na adolescência.

DAGNONI, Janine Marinho. Considerações construtivistas sobre oportunidades vulnerabilidades na adolescência. RBEP, Brasília, DF, v. 95, n. 241, p. 711-716, set./dez. 2014. Seção: Resenhas.

contrato Social de la pax capitalis: la necesidad de un juicio educativo en red. El.

MOSQUERA, Carlos Riádigos. El contrato Social de la pax capitalis: la necesidad de un juicio educativo en red. RBEP, Brasília, DF, v. 95, n. 241, p. 481-496, set./dez. 2014. Seção: Estudos.

Contribuições de uma experiência sobre o conteúdo de tratamento da informação no Programa Pró-Letramento em Matemática.

GIUSTI, Neura Maria De Rossi; JUSTO, Jutta Cornelia Reuwsaat. Contribuições de uma experiência sobre o conteúdo de tratamento da informação no Programa Pró-Letramento em Matemática. RBEP, Brasília, DF, v. 95, n. 241, p. 636-661, set./dez. 2014. Seção: Estudos.

crescimento da liberdade como fim educacional: a relação entre o pensamento reflexivo e a liberdade na obra de John Dewey. O.

CORREA, Rômulo Ferreira; MATOS, José Claudio. O crescimento da liberdade como fim educacional: a relação entre o pensamento reflexivo e a liberdade na obra de John Dewey. RBEP, Brasília, DF, v. 95, n. 239, p. 11-30, jan./abr. 2014. Seção: Estudos.

currículo de cursos técnicos de lazer no Brasil: um estudo de caso da formação profissional. 0 .

SANTOS, Carla Augusta Nogueira Lima e; ISAYAMA, Hélder Ferreira. O currículo de cursos técnicos de lazer no Brasil: um estudo de caso da formação profissional. RBEP, Brasília, DF, v. 95, n. 240, p. 276-303, maio/ ago. 2014. Seção: Estudos.

Currículos de formação de professores de língua portuguesa: instituições autônomas e o poder de sua história.

PENIN, Sonia T. S.; GALIAN, Cláudia V. A.; VALDEMARIN, Vera. Currículos de formação de professores de língua portuguesa: instituições autônomas e o poder de sua história. RBEP, Brasília, DF, v. 95, n. 239, p. 55-72, jan./ abr. 2014. Seção: Estudos. 
Defasagem idade-série em escolas estaduais de ensino médio do Rio Grande do Sul.

FRITSCH, Rosangela; VITELLI, Ricardo; ROCHA, Cleonice Silveira. Defasagem idade-série em escolas estaduais de ensino médio do Rio Grande do Sul. RBEP, Brasília, DF, v. 95, n. 239, p. 219-236, jan./abr. 2014. Seção: Estudos.

Desempenho psicomotor de escolares com dificuldades de aprendizagem em cálculos.

FERNANDES, Cleonice Terezinha; DANTAS, Paulo Moreira Silva; MOURÃO-

CARVALHAL, Maria Isabel. Desempenho psicomotor de escolares com dificuldades de aprendizagem em cálculos. RBEP, Brasília, DF, v. 95, n. 239, p. 112-138, jan./abr. 2014. Seção: Estudos.

Dinâmicas de grupo orientadas pelas atividades de estudo: desenvolvimento de habilidades e competências na educação profissional.

ALBERTI, Taís Fim et al. Dinâmicas de grupo orientadas pelas atividades de estudo: desenvolvimento de habilidades e competências na educação profissional. RBEP, Brasília, DF, v. 95, n. 240, p. 346-362, maio/ago. 2014. Seção: Estudos.

Docência em História: implicações das novas disposições curriculares do ensino médio.

PEREIRA, Nilton Mullet et al. Docência em História: implicações das novas disposições curriculares do ensino médio. RBEP, Brasília, DF, v. 95, n. 239, p. 152-174, jan./abr. 2014. Seção: Estudos.

educação em direitos humanos para amenizar os conflitos no cotidiano das escolas. A.

ZLUHAN, Mara Regina; RAITZ, Tânia Regina. A educação em direitos humanos para amenizar os conflitos no cotidiano das escolas. RBEP, Brasília, DF, v. 95, n. 239, p. 31-54, jan./abr. 2014. Seção: Estudos.

Ensino colaborativo para o apoio à inclusão escolar: práticas colaborativas entre os professores.

VILARONGA, Carla Ariela Rios; MENDES, Enicéia Gonçalves. Ensino colaborativo para o apoio à inclusão escolar: práticas colaborativas entre os professores. RBEP, Brasília, DF, v. 95, n. 239, p. 139-151, jan./abr. 2014. Seção: Estudos.

Esboço de uma compreensão da circulação de ideias: orientações para um estudo das modas educacionais.

ESTARI, Luiz Artur Santos. Esboço de uma compreensão da circulação de ideias: orientações para um estudo das modas educacionais. RBEP, Brasília, DF, v. 95, n. 240, p. 363-384, maio/ago. 2014. Seção: Estudos. 
Escola de tempo integral e ludicidade: os pontos de vista de alunos do $1^{\circ}$ ano do ensino fundamental.

AZEVEDO, Nair Correia Salgado; BETTI, Mauro. Escola de tempo integral e ludicidade: os pontos de vista de alunos do $1^{\circ}$ ano do ensino fundamental. RBEP, Brasília, DF, v. 95, n. 240, p. 255-275, maio/ago. 2014. Seção: Estudos.

Evolução dos recursos federais nos programas de transporte escolar: impactos na educação básica. A.

RIBEIRO, Andreia Couto; JESUS, Wellington Ferreira de. A evolução dos recursos federais nos programas de transporte escolar: impactos na educação básica. RBEP, Brasília, DF, v. 95, n. 241, p. 696-710, set./dez. 2014. Seção: Estudos.

Gênese das leis e dos princípios da teoria da complexidade em Edgar Morin.

MARTINAZZO, Celso José; DRESCH, Óberson Isac. Gênese das leis e dos princípios da teoria da complexidade em Edgar Morin. RBEP, Brasília, DF, v. 95, n. 240, p. 457-461, maio/ago. 2014. Seção: Resenhas.

História da pedagogia no Brasil: a contribuição das pesquisas centradas em manuais de ensino.

KULESZA, Wojciech Andrzej. História da pedagogia no Brasil: a contribuição das pesquisas centradas em manuais de ensino. RBEP, Brasília, DF, v. 95, n. 240, p. 328-345, maio/ago. 2014. Seção: Estudos.

Implantação e implementação do Proinfo no município de Bataguassu, Mato Grosso do Sul: o olhar dos profissionais da educação.

ZANDAVALLI, Carla Busato; PEDROSA, Dirceu Martins. Implantação e implementação do Proinfo no município de Bataguassu, Mato Grosso do Sul: o olhar dos profissionais da educação. RBEP, Brasília, DF, v. 95, n. 240, p. 385-413, mar./ago. 2014. Seção: Estudos.

Memorial de formação escrito no decorrer da prática docente: aprendizagens sobre alfabetização e letramento.

ALBUQUERQUE, Mayra Prates; FRISON, Lourdes Maria Bragagnolo; PORTO, Gilceane Caetano. Memorial de formação escrito no decorrer da prática docente: aprendizagens sobre alfabetização e letramento. RBEP, Brasília, DF, v. 95, n. 239, p. 73-86, jan./abr. 2014. Seção: Estudos.

Monitoria: fonte de saberes à docência superior.

DANTAS, Otilia Maria. Monitoria: fonte de saberes à docência superior. RBEP, Brasília, DF, v. 95, n. 241, p. 567-589, set./dez. 2014. Seção: Estudos. 
Montaigne: a fundamentação da educação nos moldes céticos e estoicos.

BATISTA, Gustavo Araújo. Montaigne: a fundamentação da educação nos moldes céticos e estoicos. RBEP, Brasília, DF, v. 95, n. 241, p. 497-507, set./ dez. 2014. Seção: Estudos.

Percepção dos estudantes universitários acerca do acesso à educação superior: um estudo exploratório.

FAGUNDES, Caterine Vila. Percepção dos estudantes universitários acerca do acesso à educação superior: um estudo exploratório. RBEP, Brasília, DF, v. 95, n. 241, p. 508-525, set./dez. 2014. Seção: Estudos.

Perfil, concepções e práticas pedagógicas de professores que atuam em turmas multisseriadas de escolas públicas de Sergipe.

PARENTE, Cláudia da Mota Darós. Perfil, concepções e práticas pedagógicas de professores que atuam em turmas multisseriadas de escolas públicas de Sergipe. RBEP, Brasília, DF, v. 95, n. 241, p. 676-695, set./dez. 2014. Seção: Estudos.

Políticas públicas de democratização do acesso ao ensino superior e estrutura básica de formação no ensino médio regular.

CARMO, Erinaldo Ferreira et al. Políticas públicas de democratização do acesso ao ensino superior e estrutura básica de formação no ensino médio regular. RBEP, Brasília, DF, v. 95, n. 240, p. 304-327, maio/ago. 2014. Seção: Estudos.

Profesores de educación: perfiles y prácticas profesionales.

EUGENIA VICENTE, María. Profesores de educación: perfiles y prácticas profesionales. RBEP, Brasília, DF, v. 95, n. 241, p. 590-608, set./dez. 2014. Seção: Estudos.

Quando o jogo na escola é bem mais que jogo: possibilidades de intervenção pedagógica no jogo de regras Set Game.

CARVALHO, Luciana Ramos Rodrigues de; OLIVEIRA, Francismara Neves de. Quando o jogo na escola é bem mais que jogo: possibilidades de intervenção pedagógica no jogo de regras Set Game. RBEP, Brasília, DF, v. 95, n. 240, p. 431-455, maio/ago. 2014. Seção: Estudos.

que revelam as pesquisas sobre a atuação do coordenador pedagógico. $O$. MIZIARA, Leni Aparecida Souto; RIBEIRO, Ricardo; BEZERRA, Giovani Ferreira. O que revelam as pesquisas sobre a atuação do coordenador pedagógico. RBEP, Brasília, DF, v. 95, n. 241, p. 609-635, set./dez. 2014. Seção: Estudos. 
Sujeito, educação e o trabalho com a Língua Portuguesa na escola básica.

MAGALHÃES, Tânia Guedes; CYRANKA, Lucia Furtado de Mendonça. Sujeito, educação e o trabalho com a Língua Portuguesa na escola básica. RBEP, Brasília, DF, v. 95, n. 241, p. 662-675, set./dez. 2014. Seção: Estudos.

transposição didática na educação física escolar: o caminho formativo dos professores em formação inicial. A.

MARTINY, Luis Eugênio; GOMES-DA-SILVA, Pierre Normando. A transposição didática na educação física escolar: o caminho formativo dos professores em formação inicial. RBEP, Brasília, DF, v. 95, n. 239, p. 175198, jan./abr. 2014. Seção: Estudos. 